
Informations

une revue Gallia

Lorraine | 2001

\title{
Norroy-le-Veneur
}

Lotissement "Les Quatre Saisons"

\section{Marc Feller}

\section{(2) OpenEdition}

1 Journals

Édition électronique

URL : http://journals.openedition.org/adlfi/8990

ISSN : 2114-0502

Éditeur

Ministère de la culture

Référence électronique

Marc Feller, " Norroy-le-Veneur », ADLFI. Archéologie de la France - Informations [En ligne], Lorraine, mis en ligne le 01 mars 2001, consulté le 03 mai 2019. URL : http://journals.openedition.org/adlfi/8990

Ce document a été généré automatiquement le 3 mai 2019.

(c) Ministère de la Culture et de la Communication, CNRS 


\title{
Norroy-le-Veneur
}

\author{
Lotissement "Les Quatre Saisons"
}

\author{
Marc Feller
}

Identifiant de l'opération archéologique : F1357200100102

Date de l'opération : 2001 (SU)

Un projet de lotissement envisagé de chaque côté de la route qui mène du hameau de Bellevue à la ferme Sainte-Anne a amené la réalisation de fouilles archéologiques qui se sont déroulées tout au long du mois de mai 2001.

Cette opération d'archéologie préventive a permis de déceler des traces d'occupation humaine datable de la Protohistoire (âge du Bronze final) et d'étudier les restes d'un bâtiment remontant à la période gallo-romaine.

Les vestiges du Bronze final étaient constitués de deux fosses et quelques emplacements de poteaux qui laissent présumer l'existence d'un habitat à proximité.

Les vestiges de la période gallo-romaine étaient formés par les restes d'un grand bâtiment en partie situé sous la route, par les fondations d'un grenier et des éléments de parcellaire.

Du bâtiment, dont nous n'avons pu dresser qu'un plan incomplet, il ne subsistait que les tranchées de fondation épierrées et comblées avec un remblai organique. Cet édifice présentait un corps rectangulaire, de $25 \mathrm{~m} \times 19 \mathrm{~m}$, précédé par un avant-corps formé de deux tours. Celles-ci étaient reliées entre elles par une galerie comportant certainement un escalier. L'intérieur était subdivisé en une grande pièce centrale de $160 \mathrm{~m}^{2}$ encadrée sur le côté et à l'arrière par des pièces allongées. L'embase d'un petit grenier de 3,50 m $\mathrm{x} 4,10 \mathrm{~m}$ se trouvait à proximité.

Ces deux constructions recoupent un système de fossés préexistant dont elles reprennent rigoureusement l'orientation. Ce réseau, orienté $27^{\circ}$ ouest, présente des tronçons parallèles et orthogonaux. Il semble vraisemblable qu'il s'agisse d'éléments d'un 
parcellaire mis en place au début de la période antique, peut être en relation avec la voie romaine Metz-Trèves, par la rive gauche de la Moselle, située non loin.

En avant du bâtiment, deux drains en pierre sèche permettaient aux eaux pluviales d'être évacuées plus loin dans la pente ; de même de l'autre côté du chemin un large système de drainage permettait d'évacuer l'eau vers le ruisseau situé en contrebas.

Cet aménagement est à mettre en relation avec plusieurs fragments de matériaux de construction en terre cuite qui permettent de penser que ce bâtiment disposait d'une aile thermale située à l'emplacement de la route.

Différents objets ont été découverts lors de la fouille. Il s'agit essentiellement de vaisselle de table et d'ustensiles culinaires en terre cuite qui montrent que nous sommes en présence d'un habitat qui a été occupé de la fin du I ${ }^{\mathrm{er}} \mathrm{s}$. de notre ère jusqu'au milieu du III ${ }^{\mathrm{e}} \mathrm{s}$. de notre ère. Les observations réalisées amènent à penser que la récupération des divers matériaux disponibles suite à l'abandon du site s'est faite dès la période romaine.

(Fig. $n^{\circ} 1$ : Plan général du site)

\section{ANNEXES}

Fig. $\mathrm{n}^{\circ} 1$ : Plan général du site

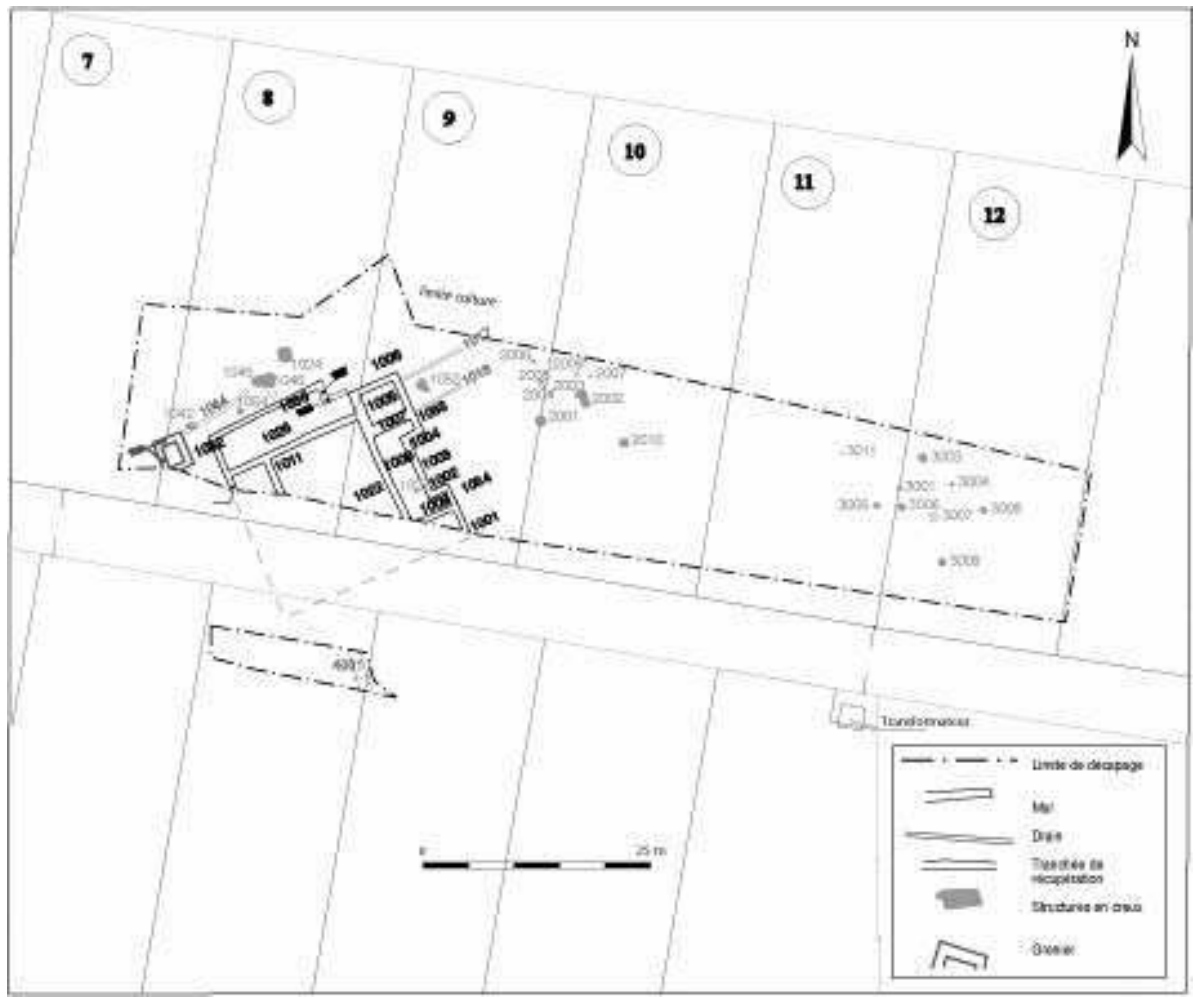

$\operatorname{INRAP}(2001)$ 
INDEX

operation Sauvetage urgent (SU)

Index chronologique : âge du Bronze, Empire romain

Thèmes : drain, drainage, édifice, escalier, fosse, galerie, grenier, habitat, parcellaire, thermes privés, tour, trou de poteau, vaisselle

Index géographique : Lorraine, Moselle (57), Norroy-le-Veneur

AUTEURS

MARC FELLER 